\title{
DE EICHMANN EN JERUSALÉN A LOS «JUICIOS» EN ARGENTINA (REFLEXIONES SITUADAS)
}

CLAUDIA HILB

\author{
Claudia Hilb es Investigadora del CONICET, \\ en el Instituto de Investigaciones «Gino Germani» \\ de la Universidad de Buenos Aires y Profesora \\ de la Facultad de Ciencias Sociales \\ de la misma universidad. \\ e-mail: hilb@fibertel.com.ar
}

Al inicio del epílogo de su crónica del juicio de Eichmann en Jerusalén, Hannah Arendt afirma que dicho juicio nos coloca frente a problemas políticos, morales y jurídicos que sin embargo el juicio mismo, por cómo fue llevado adelante, lejos de ayudarnos a elucidar, contribuye a oscurecer. Me propongo aquí restablecer brevemente cuáles son, a ojos de Arendt, estos problemas políticos, morales y jurídicos, a fin de apoyarme en su reflexión para interrogar, a partir de allí, cuáles pueden ser los problemas políticos, morales y jurídicos con los que nos confronta el juzgamiento, en Argentina, de los autores de los crímenes cometidos por la dictadura militar que asoló el país entre 1976 y 1983.

Como es sabido, Arendt afirma repetidamente, desde los años cuarenta, que el totalitarismo ha hecho estallar las categorías morales y jurídicas de las que disponíamos, al confrontarnos a un nuevo tipo de crimen -la vocación por convertir al hombre en superfluo, y la eliminación de poblaciones enteras de la faz de la tierra-, y a un nuevo tipo de criminal, que no puede captarse en los términos habituales de quien infringe -a sabiendas, o por inadvertencia- las normas compartidas, $y$ que sólo parecemos poder captar vagamente si nos referimos a lo que Kant, sin ir sin embargo mucho más lejos, denominó «mal radical». En los primeros años Arendt insistirá en que nos encontramos inermes, que sólo podemos decir de estos crímenes que no deberían haber sucedido, y que no podemos castigarlos ni perdonarlos en tanto no podemos comprenderlos, puesto que no son subsumibles bajo las categorías con las que comprendemos y juzgamos. Esos crímenes y esos 
criminales parecen exceder, en su radicalidad maligna, la esfera de los asuntos entre hombres, que es la escena común en que actuamos, y en que podemos comprender, juzgar y así castigar, o también perdonar. Y no obstante, aunque carezcamos de las herramientas para hacerlo, debemos juzgarlos y castigarlos. Como escribe en «La imagen del infierno» (1946), «es tan necesario castigar a los culpables como recordar que no existe castigo que pudiera corresponder a sus crímenes» ${ }^{1}$.

Ahora bien, desde sus primeras manifestaciones en este sentido hasta su crónica del juicio de Jerusalén, Arendt se habrá abocado, precisamente, a la tarea de comprender. De comprender "qué sucedió» -y los Orígenes del totalitarismo marca sin dudas un hito fundamental en esta empresa- y de comprender «cómo fue posible que sucediera $»^{2}$. En ese trayecto, irá afinando y modificando su reacción primera respecto del nuevo tipo de criminal, y su insinuación originaria, que parecía apuntar al carácter radical de la maldad del autor de este nuevo tipo de crímenes, irá dejando lugar a la configuración de otra figura, a la del criminal banal, la de aquel que está dispuesto a adscribir a cualquier máxima, sea cual fuere, que le sea dada. No parece haber, en ese personaje, ningún atisbo de maldad diabólica, de aquello que -al sobrepasar lo asible en el concepto- correría el riesgo de codearse con lo sublime $^{3}$. Se trata, por el contrario, de alguien a quien apenas puede corresponder el nombre de persona, si llamamos persona, con Arendt, a quien resguarda en sí la

${ }^{1}$ Hannah Arendt, «The Image of Hell», en: Commentary 2/3, septiembre de 1946, pp. 291-295, republicado en Hannah Arendt, Essays in Understanding, edición e introducción de Jerome Kohn, Nueva York, Schocken Books, 1994, p. 200.

${ }^{2}$ Cf. Hannah Arendt, «Preface to Part Three» en: The Origins of Totalitarianism, Nueva York/San Diego/ Londres, Harcourt Inc., p. xxiv.

${ }^{3}$ Ya en 1946 en una carta a Karl Jaspers, ante las objeciones de éste, Arendt reconocía la necesidad de precaverse contra la idea de una «grandeza satánica» en el nuevo mal: «me doy cuenta completamente de que en el modo en que he expresado esto hasta ahora me acerco peligrosamente a la cgrandeza satánicas que al igual que Ud. rechazo totalmente. Pero no obstante, existe una diferencia entre un hombre que se propone asesinar a su vieja tía y gente que sin tomar en consideración la utilidad económica de sus acciones (...) construye fábricas para producir cadáveres. Una cosa es indudable: debe combatirse cualquier intento de mitologizar el horror, y hasta tanto no logre yo extraerme de este tipo de formulaciones no habré entendido realmente qué sucedió». Hanna Arendt/Karl Jaspers, Briefwechsel 1926-1969, Münich, Piper, 1985, carta 50, 17 de diciembre de 1946, p. 106. 
pluralidad propia de la condición humana ${ }^{4}$; se trata de aquel que está dispuesto a hacer cualquier cosa, a subsumir sus actos bajo cualquier norma que se le proponga, porque ha renunciado a pensar, porque ha renunciado al diálogo consigo mismo, porque ha renunciado a la interrogación acerca de lo que está bien y lo que está mal. No obstante, no por el hecho de haber comprendido algo más, la pregunta acerca de cómo juzgar, cómo castigar este nuevo arquetipo de criminal autor de un nuevo tipo de crímenes, se ha vuelto más sencilla. Si en los ańos cuarenta Arendt insinuaba que el mal radical no poseía castigo a la medida de ese mal, y escapando a la esfera de los asuntos humanos sólo podía convocar a la retribución o la venganza, el agente banal del mal extremo con que nos confronta su reflexión en los años sesenta no nos deja en mejor situación para juzgar. Porque un agente tal nos sustrae aquello que, desde siempre, ha estado en nuestra tradición unido a la posibilidad de castigar el crimen: esto es, nos priva de la conciencia, de la voluntad de actuar en contra de la ley que atribuimos necesariamente al criminal, para considerarlo tal.

Si a ojos de Arendt el juicio de Jerusalén debe evaluarse en buena medida como un fracaso, esto se debe a que -pese al hecho no menor de haber condenado a Eichmann- no ha contribuido a esclarecer los problemas morales, políticos y jurídicos con los que nos confronta, sino que por el contrario los ha oscurecido. Para lo que aquí me interesa, ha obturado la comprensión de que (1) nos encontramos frente a un nuevo tipo de crimen para el cual no disponemos de leyes, y que convoca entonces o bien a leyes que no dan cuenta de la novedad del fenómeno ni cuadran con los nuevos crímenes cometidos, o bien a leyes de nuevo tipo que deberán aplicarse retroactivamente; y de que (2) nos enfrentamos a un nuevo tipo de criminal, que como señalaba, no cree ser responsable de otra cosa que de haber cumplido con eficacia las órdenes y leyes bajo las cuales ejerció su tarea. Si el primer problema pone en jaque nuestras categorías jurídicas, el segundo interpela, asimismo, nuestras categorías morales respecto de la relación entre culpa, responsabilidad y conciencia moral.

\footnotetext{
4 «Pensar y recordar, dijimos, es la manera humana de echar raíces (...) Aquello que comúnmente llamamos una persona o una personalidad, en tanto se distingue de un mero ser humano o de un nadie, de hecho surge de este proceso enraizador del pensar». Hanna Arendt, «Some Questions of Moral Philosophy", en: Hannah Arendt, Responsibility and Judgment, Nueva York, Schocken Books, 2003, p. 100. 0 también: «En el mal que carece de raíces (rootless) no queda persona alguna a la que poder siquiera perdonar» (Ídem, p. 95).
} 
La dificultad ante la que nos hallamos, y que el juicio no ha contribuido a esclarecer, está expresada en los párrafos finales del epílogo de Eichmann en Jerusalén; y la interpretación de la postura de Arendt frente a los problemas suscitados por el juicio se dirime, entiendo, en la atenta meditación de esas líneas. Allí, recurriendo a una cita de Yosal Rogat, Arendt escribe: «rechazamos, y las consideramos bárbaras, las afirmaciones de que los grandes delitos ofenden de tal modo a la naturaleza, que incluso la tierra clama venganza; que el mal viola la natural armonía de tal manera que tan solo la retribución puede restablecerla; que las comunidades ofendidas por el delito tienen el deber moral de castigar al delincuente ${ }^{5}$. Esto es, rechazamos como bárbara la idea de que hay crímenes que violan la armonía natural de modo tal que es nuestro deber moral retribuir el mal con la venganza y el castigo. Pero a la vez, frente a este mal novedoso, extremo, para el cual no disponemos de instrumentos de justicia que se hallen a la medida de su novedad y su radicalidad, no disponemos de una alternativa de castigo que pueda prescindir de la venganza, o que no contraríe nuestros principios corrientes de justicia que objetan que apliquemos, con el poder que nos otorga la victoria, una nueva ley de manera retroactiva, a la medida del nuevo crimen ${ }^{6}$.

Hay así, en el juicio de Israel, un elemento trágico in-asimilable: debemos hacer actuar a la justicia, aun si no sabemos cómo hacerlo, o más aún, aun si no estamos en condiciones de hacerlo ${ }^{7}$. Y puesto que debemos hacerlo, la justicia que de allí resultará esconderá bajo sus ropajes los elementos de la venganza, de la retribución, afirmados en nuestra certeza de que los grandes delitos que ha

\footnotetext{
${ }^{5}$ Hannah Arendt, Eichmann in Jerusalem. A report on the banality of evil, Nueva York, The Viking Press, 1963, p. 277.

${ }^{6}$ Arendt no objeta que se aplique una ley retroactiva, ya que entiende que nuevos crímenes, los crímenes contra la humanidad, convocan inevitablemente la necesidad de nuevas leyes. Lamenta, en cambio, que el juicio de Eichmann no haya redundado en la conformación de un tribunal penal internacional, que podría haberse constituido como nueva instancia duradera para afrontar este nuevo tipo de crimen hacia el futuro, y que en cambio haya constituido el último en la serie de los «juicios sucesorios» de Nuremberg, es decir, de juicios instrumentados por los vencedores.

${ }^{7}$ En un excelente artículo, Susannah Young-ah Gottlieb ha señalado que si asimilamos esta situación a la tragedia, el héroe de la misma ciertamente no sería Eichmann, sino los jueces que deben pronunciar una justicia para la cual no tienen palabras adecuadas. Susannah Young-ah Gottlieb, «Beyond tragedy: Arendt, Rogat and the Judges in Jerusalem», en: College Literature, 38/1, 2011, pp. 45-56.
} 
cometido Eichmann «ofenden de tal modo a la naturaleza, que incluso la tierra clama venganza; que el mal viola la natural armonía de tal manera que tan solo la retribución puede restablecerla». Es en esa clave que debemos interpretar los extraños ecos del alegato que Arendt pone en boca de los jueces, de aquello que según Arendt los jueces deberían haber dicho si hubieran dado efectiva cuenta del principio de su accionar. Ese supuesto alegato diría así que

«del mismo modo que Ud. apoyó y cumplimentó una política de unos hombres que no deseaban compartir la tierra con el pueblo judío ni con ciertos otros pueblos de diversa nación -como si Ud. y sus superiores tuvieran el derecho de decidir quién puede y quién no puede habitar el mundo-, nosotros consideramos que nadie, es decir, ningún miembro de la raza humana, puede desear compartir la tierra con Usted. Esta es la razón, la única razón, por la que debe ser colgado» ${ }^{8}$.

No importa, para el caso, que Eichmann no se sienta culpable, que no crea haber cometido un delito: percibimos la obligación moral de castigarlo, aunque esta obligación moral no pueda encontrar otro fundamento que nuestra certeza arcaica, bárbara, de que-aunque los crímenes excedan nuestras categorías, aunque sus agentes no se sientan culpables- hay males que exigen castigo. Que es justo que Eichmann deba morir.

En otras palabras, el juicio de Jerusalén oculta, malamente, que nuestra convicción de que al condenarse a Eichmann se ha hecho justicia no puede fundarse en nuestros principios morales y jurídicos explícitos, sino en una remisión a una relación arcaica, cuasi natural, a lo justo, y a nuestra negativa a admitir que hombres normales puedan renunciar a la capacidad de distinguir el bien del mal. ¿Es esta relación arcaica a lo justo y esta imputación universal de la capacidad de distinguir el bien del mal, en ausencia o en oposición a normas impartidas, un fundamento suficiente, satisfactorio, de nuestra acción, que es nada menos que la condena de Eichmann a la horca? Allí, claro está, reside la pregunta que el texto de Arendt pone en escena de manera extraordinaria, en la incomodidad que nos suscita la conclusión, «es por eso que Ud. debe ser colgado». Y en ese sentido, el juicio de Eichmann pone ante nosotros las preguntas morales, jurídicas y políticas que

\footnotetext{
${ }^{8}$ Hannah Arendt, Eichmann in Jerusalem, op. cit., p. 279.
} 
debemos enfrentar una vez que hemos perdido las certezas con las que, hasta no hace tanto tiempo, nos orientábamos sin mayor dificultad en el mundo común?

Inspirados en nuestro recorrido de Eichmann en Jerusalén intentemos ahora hacer surgir las preguntas a las que nos conminan los juicios en Argentina a los agentes del terror estatal. No ignoro, claro está, las diferencias monumentales que separan ambos casos, pero creo aun así que el texto de Arendt puede ayudarnos a pensar lo que queremos pensar. Centraré mi reflexión sobre dos momentos: el primero, el período que conduce a los Juicios a las Juntas Militares bajo el gobierno de Raúl Alfonsín en 1985, y la posterior sanción en 1987, bajo ese mismo gobierno, de las leyes de «Obediencia Debida» y de «Punto Final» ${ }^{10}$; el segundo, la reapertura de los juicios por delitos de lesa humanidad cometidos bajo el régimen militar de 1976-1983, a partir del año 2005, tras la declaración de nulidad en 2003 de las leyes de 1987, seguida en 2007 por la declaración de inconstitucionalidad de los indultos firmados por el presidente Carlos Menem en $1990^{11}$.

En ambos casos, y de manera distinta como veremos, la percepción de que ha sucedido entre nosotros un crimen sin precedentes, la exterminación clandestina de un grupo de personas -no importa, para ello, si son diez mil o treinta mil- organizada desde el Estado ${ }^{12}$, convoca a la certeza de que «un crimen tal merece castigo». En ambos casos el crimen, en su naturaleza de crimen organizado desde el poder del Estado, involucrando a centenas o miles de agentes, parece no tener precedentes que nos permitirían sin dificultad aplicar las herramientas jurídicas existentes.

\footnotetext{
${ }^{9}$ En «Personal responsibility under dictatorship», Arendt escribe: «mi formación intelectual temprana ocurrió en una atmósfera en la que nadie prestaba mucha atención a los asuntos morales; fuimos criados con el supuesto: Das Moralische versteht sich von selbst, la conducta moral va de suyo». Hanna Arendt, «Personal responsibility under dictatorship», en: Hanna Arendt, Responsibility and Judgment, op. cit., pp. 22-23.

${ }^{10}$ Como es sabido, estas leyes pusieron fin a la posibilidad de procesar a la gran mayoría de los integrantes de las fuerzas militares y de seguridad por actos cometidos entre 1976 y 1983.

${ }^{11}$ Recordemos que los indultos de 1990 habían beneficiado no sólo a los condenados en los Juicios de 1985 o en juicios posteriores, sino también a quiénes se encontraban bajo proceso.

${ }^{12}$ Existe en Argentina una disputa, más política que historiográfica, acerca del número de víctimas de la dictadura. Por mi parte entiendo que el crimen es igualmente monstruoso en su naturaleza, y sin precedentes entre nosotros, tanto si limitamos sus víctimas a las casi 10.000 personas documentadas en su totalidad en el trabajo de la Conadep y otras recolecciones posteriores de fuentes, como si las extendemos a los 30.000 , como sostienen algunos organismos de Derechos Humanos.
} 
Así, yendo al primer momento, ya cuando releemos las palabras finales del fiscal Strassera en el Juicio a las Juntas ${ }^{13}$, o cuando recorremos los argumentos del libro de Carlos Nino, Juicio al mal absoluto ${ }^{14}$, que relata las discusiones que rodearon la preparación de esos juicios entre los asesores cercanos al presidente Alfonsín, percibimos la convicción de que, poseamos las herramientas idóneas o no, esos crímenes deben ser castigados. Pero en uno y otro caso, en toda la letra del libro de Nino, o en las referencias de Strassera a los problemas de la justicia retributiva, percibimos al mismo tiempo y en todo momento la preocupación por encontrar en el orden institucional recuperado esas herramientas jurídicas idóneas, para escapar así cuanto se pueda a todo atisbo de excepcionalidad.

Si resituamos esta preocupación en los términos que nos provee Arendt, podemos decir que encontramos desde 1983 la percepción de la novedad del crimen, frente a la cual no tenemos propiamente herramientas precisas, acompañada de la certeza, anclada firmemente en nuestro sentido de justicia, de que hay crímenes que merecen castigo, pero que hallamos también simultáneamente en aquel momento el intento de soslayar la novedad del crimen, de subsumirlo bajo reglas conocidas, a fin de escapar así a todo parecido con una justicia de vencedores que pudiera prevalerse de su supremacía para imponer leyes excepcionales o retroactivas. Podemos avanzar: en aquella primera instancia los problemas a los que refiere Arendt parecen percibirse -el problema del crimen inédito, de la ausencia de pena a la medida del crimen, y a la vez, de la necesidad de castigarlo- y la solución buscada es disimularlos, hasta donde sea posible, bajo el manto de la normalidad. Pero esto, claro, sólo es posible parcialmente. Y allí donde el sentido ofendido de justicia -el problema moral, podemos decir- choca con el intento de ocultar las dificultades bajo el manto de

13 «Por todo ello, señor presidente, este juicio y esta condena son importantes y necesarios para la Nación argentina, que ha sido ofendida por crímenes atroces. Su propia atrocidad torna monstruosa la mera hipótesis de la impunidad. Salvo que la conciencia moral de los argentinos haya descendido a niveles tribales, nadie puede admitir que el secuestro, la tortura o el asesinato constituyan hechos políticos o contingencias del combate».

«Ahora que el pueblo argentino ha recuperado el gobierno y control de sus instituciones, yo asumo la responsabilidad de declarar en su nombre que el sadismo no es una ideología política ni una estrategia bélica, sino una perversión moral». Alegato final del Fiscal Strassera en el Juicio a las Juntas. Disponible en: http://archivohistorico.educ.ar/sites/default/files/IX_04.pdf (último ingreso: 02/11/2014). ${ }^{14}$ Carlos Nino, Juicio al mal absoluto, Buenos Aires, Emecé, 1997. 
normalidad -ocultando el problema jurídico, como si este no existiera-, la solución hace crisis: en el punto 30 del fallo del Juicio a las Juntas, o en las excepciones que introduce el Senado a la "Obediencia Debida» en la reforma del Código Militar. En efecto, aquel punto 30 del fallo en el Juicio a las Juntas, contrariando el intento de limitar los juicios a los acusados en aquel momento, establecía que correspondía enjuiciar no sólo «a los Oficiales Superiores, que ocuparon los comandos de zona y subzona de Defensa, durante la lucha contra la subversión» sino también a «todos aquellos que tuvieron responsabilidad operativa en las acciones» ${ }^{15}$.

Con esa sencilla afirmación, la extensión de la imputabilidad se ampliaba considerablemente, más allá de lo previsto por el Gobierno. Asimismo, la modificación introducida por el Congreso al proyecto de reforma al código militar, una de cuyas finalidades era reglamentar la "Obediencia Debida» a fin de exonerar a los mandos inferiores - una modificación que el Poder Ejecutivo sorprendentemente no vetó- había establecido ya que la «Obediencia Debida» no podía argüirse en caso de hechos atroces o aberrantes ${ }^{16}$. Nuevamente, el propósito de limitar los alcances de la justicia por un lado, chocaba por el otro con la necesidad, empujada por una suerte de impulso moral, de ampliarlos. Así, podemos advertir, el intento alfonsinista de esconder, bajo los ropajes de la legalidad, la excepción ineludible a la que se ve confrontada frente a crímenes sin precedentes que demandan castigo,

\footnotetext{
${ }^{15}$ El punto 30 de dicho fallo dice así: «30) Disponiendo, en cumplimiento del deber legal de denunciar, se ponga en conocimiento del Consejo Supremo de las FF.AA., el contenido de esta sentencia y cuantas piezas de la causa sean pertinentes, a los efectos del enjuiciamiento de los Oficiales Superiores, que ocuparon los comandos de zona y subzona de Defensa, durante la lucha contra la subversión, y de todos aquellos que tuvieron responsabilidad operativa en las acciones (arts. 387 del Código de Justicia Militar y 164 del Código de Procedimientos en Materia Penal)».

16 Ley 23.049 de Reforma del Código Militar (febrero 1984): Art. 11 - «El art. 34, inc. 5 del Código Penal deberá ser interpretado conforme a la regla del art. 514 del Código de Justicia Militar respecto de los hechos cometidos por el personal mencionado en el artículo anterior que actuó sin capacidad decisoria cumpliendo órdenes o directivas que correspondieran a planes aprobados y supervisados por los mandos superiores orgánicos de las Fuerzas Armadas y por la Junta Militar. A ese efecto podrá presumirse, salvo evidencia en contrario que se obró con error insalvable sobre la legitimidad de la orden recibida, excepto cuando consistiera en la comisión de hechos atroces o aberrantes». La reforma tenía como finalidad central reglamentar el paso del fuero militar a la justicia civil en caso de que las FFAA, como sucedió, omitieran auto-depurarse; era objetada por los defensores militares por su efecto retroactivo (como lo era también la derogación de la auto-amnistía decretada por la Dictadura en septiembre de 1983).
} 
deja traslucir sus dificultades, o sus imposibilidades, en esos momentos clave, en que el sentido de la justicia dañada se sobresalta frente a la inadecuación del orden jurídico. Con la clausura del momento alfonsinista con las leyes de «Obediencia Debida» y «Punto Final» de 1987, esa crisis encuentra una resolución que ahora es abiertamente, eminentemente, política ${ }^{17}$.

Cuando recorremos los principios que parecen subyacer al proceso que, a partir de 2003, conducirá a la reapertura de los juicios en 2005, percibimos que aquella voluntad de subsumir, hasta donde fuera posible, los juicios bajo la normalidad de las reglas previas parece haber perdido toda importancia. La excepcionalidad es asumida casi abiertamente, en nombre del sentido ofendido de justicia: si la clausura política de 1987, aumentada por los indultos de Menem, han instalado una sensación si no universal, por lo menos bastante extendida de impunidad, la oposición a la impunidad en nombre del sentido ofendido de la justicia -hay crímenes que no deben permanecer impunes- parece dar el tono dominante del camino emprendido. La declaración de nulidad de las leyes del Parlamento de 1987, la derogación de los indultos, el desconocimiento de la cosa juzgada, el juzgamiento de los crímenes como crímenes de lesa humanidad (una figura incorporada a la Constitución en 1994, o sea posterior a los hechos), todas estas medidas altamente discutibles desde la óptica del Estado de derecho, se justifican esencialmente en nombre de la necesidad de juzgar crímenes que exigen castigo ${ }^{18}$. Y si en 1985 la

${ }^{17}$ Esa solución, avalada por la Corte Suprema, implicaba asimismo un cierre jurídico de legalidad cuestionable, puesto que prohibía a la justicia examinar siquiera los casos subsumibles a priori bajo la figura de la obediencia debida, lo cual podía interpretarse como un avasallamiento de la independencia del Poder Judicial.

${ }^{18}$ No podemos detallar aquí el proceso político y jurídico que condujo a partir de 2003 a este conjunto de medidas. Señalemos brevemente que en el terreno político el hito mayor fue la declaración de nulidad por parte del Congreso de las leyes de «Obediencia Debida» y «Punto Final» en ese año 2003. En el campo jurídico, el proceso de reapertura de los juicios se consolidó sobre tres fallos de la Corte Suprema (que en términos generales rechazó la validez de la nulidad determinada por el Congreso): en 2003 el fallo en el caso Arancibia Clavel declaró el carácter imprescriptible de los crímenes contra la humanidad, en 2005 el fallo en el caso Simón dictaminó la ilegalidad de las leyes de «Obediencia Debida» y «Punto Final» (que una Corte anterior había avalado, en 1987), y en 2007 el fallo en el caso Riveros determinó la ilegalidad de los indultos. Es interesante observar que en cada uno de esos momentos las decisiones de la Corte dieron lugar a votos en disidencia, con fundamentaciones diversas, por parte de algunos de sus miembros -y no siempre de los mismos-. Así, por ejemplo, Carmen Argibay sostuvo el argumento de la ley más benigna para fundamentar su oposición a la anulación 
búsqueda estuvo orientada a ocultar la excepción bajo la regla, a partir de 2003 la referencia a los juicios de Nüremberg, juicios excepcionales realizados por los vencedores, resulta por el contrario un aval de peso en la afirmación de la prioridad de la justicia por encima de la seguridad jurídica, para utilizar la expresión del ministro de la Corte Suprema de Justicia Ricardo Lorenzetti ${ }^{19}$. Nuestro sentido de justicia exige castigo, y si para castigar no disponemos de las herramientas idóneas nuestra voluntad de justicia habrá de procurarlas ${ }^{20}$.

Nuestro sentido de justicia se ha visto ofendido. Pero ¿̨cuál ha de ser la medida de ese castigo, cuando no disponemos de los instrumentos jurídicos idóneos? ¿Cómo escapar de la justicia de los vencedores, cuando aplicamos leyes retroactivamente, cuando derogamos leyes legítimamente sancionadas, cuando desconocemos la cosa juzgada? En lo que aquí me interesa, ¿nos provee esta reapertura mayor claridad para pensar los problemas morales, jurídicos y políticos a los que nos vemos confrontados, o los da por resueltos en la afirmación de que un crimen tal merece castigo? Al final del epílogo a Eichmann en Jerusalén Arendt nos da a entender que en el entrelazamiento del sobresalto de nuestro sentido de la justicia -un crimen tal merece castigo- y nuestra imposibilidad de encontrar en las normas establecidas la medida de ese castigo, recurre, bajo las formas aparentes de la justicia, el círculo trágico de la venganza, de la retribución del mal por el mal. La celebración de la reapertura de los juicios, de la persecución de los criminales, no debe obturar que examinemos esta posibilidad: de que también entre nosotros la afirmación de un

del indulto en el caso de Santiago Omar Riveros, aprobado por la Corte por cuatro votos contra dos, y una abstención, que posibilitaría luego la anulación del resto de los indultos dictados por Menem en 1990. Para una información más completa véase, entre otros, Centro de Estudios Legales y Sociales (CELS), Derechos Humanos en Argentina: Informe 2013, Buenos Aires, Siglo XXI, 2013; Hacer justicia: nuevos debates sobre el juzgamiento de crímenes de lesa humanidad en Argentina, Buenos Aires, Siglo XXI, 2011; Memoria Abierta, Abogados, derecho y política, Buenos Aires, Memoria Abierta, 2010. ${ }^{19}$ Ver Ricardo Lorenzetti y Alfredo J. Kraut, Derechos humanos: justicia y reparación, Buenos Aires, Sudamericana, 2011, pp. 41-42.

${ }^{20}$ El crimen, aquí, no nos es desconocido como lo es el genocidio para Arendt: es el crimen de lesa humanidad. Y aunque este no haya formado parte de nuestro ordenamiento jurídico, Lorenzetti argumenta que encontramos en nuestra tradición de derecho natural, o del derecho de gentes o en nuestra certidumbre, «que son reconocibles para una persona que obrara honestamente conforme a los principios del estado de derecho", suficiente apoyo para poder sostener su pertinencia (Ibídem). Señalemos en contraste que en 1985 se omitió juzgar con la figura del genocidio, por no estar ésta incluida en la Constitución. 
sentido arcaico, insoslayable, de justicia, en ausencia de las herramientas jurídicas que pudieran enfrentar el mal advenido, no pueda evitar la comparecencia del círculo trágico de la retribución del mal con el mal. De que la afirmación de un sentido insoslayable de justicia se mezcle, de manera casi imperceptible, con la celebración de una justicia de los vencedores. De que entonces, la convicción de detentar en nuestras manos el sentido de lo justo, situado con certeza por encima de los instrumentos jurídicos, convierta el triunfo sobre la impunidad en la imposición de una justicia parcial, injusta, que cree saber demasiado, que cree saber a priori quiénes son culpables y quiénes inocentes, en una afirmación de lo justo desinteresada del estado de derecho y de los derechos de los acusados.

La celebración de la extensión, en los tiempos actuales, del delito de lesa humanidad-única figura imprescriptible de la que disponemos, pero a la vez, recordemos, retroactiva respecto de los delitos juzgados-a los llamados «cómplices civiles» de la dictadura parece insistir en ese sentido: aunque no dispongamos de instrumentos idóneos, sabemos dónde está el bien, donde está el mal, y por él vamos. No parece haber complejidades ni claro-oscuros de nuestro pasado reciente que resistan a esta convicción. Pero de pronto, así como el punto 30, o la enmienda del Senado referido a delitos aberrantes y horrendos, pusieron en los ańos ochenta tácitamente ante nuestros ojos la imposibilidad de subsumir bajo la normalidad aquello que escapaba a ella -la necesidad de juzgar crímenes horrendos, sin precedentes-ahora las excepciones a la excepcionalidad ponen también ante nuestros ojos los problemas morales, políticos y jurídicos ocultos bajo el entusiasmo punitivo. El caso Milani ha puesto en evidencia que la vocación de extender el castigo sin establecer niveles de responsabilidad entre los partícipes de los crímenes considerados de lesa humanidad choca, aun para sus defensores acérrimos, con sus intuiciones morales, sus presupuestos jurídicos y sus convicciones políticas y ha puesto, o debería haber puesto, un signo de pregunta sobre la celebrada extensión indiscriminada de la culpabilidad a los mandos menores de las Fuerzas Armadas ${ }^{21}$. Del mismo modo, el

${ }^{21}$ Como es sabido, César Milani, Jefe del Ejército nombrado por la presidente Cristina F. de Kirchner, está sospechado de haber participado en hechos sindicados como crímenes de lesa humanidad cuando revistaba como teniente durante la dictadura. El Poder Ejecutivo y el partido gobernante lo han defendido a rajatabla, y la fiscalía parece haber actuado en sentido opuesto al habitual, al buscar evitar su persecución en la Justicia. Al respecto, me permito remitir a Claudia Hilb, «Reflexiones sobre el caso Milani», Anuario 2014. Lucha Armada en Argentina, Buenos Aires, Ejercitar la memoria editores, 2014. 
caso del matrimonio Hurban, los padres de crianza de Ignacio Montoya Carlotto, ha producido una grieta evidente en el discurso público de quienes parecían, hasta entonces, no tener dudas respecto de la distinción neta entre culpables e inocentes cuando de apropiación de nińos se trataba ${ }^{22}$.

Las dificultades del tratamiento jurídico de los años ochenta condujeron, como señalábamos, a la clausura política de las preguntas, clausura que fue, con el tiempo, sedimentando como una capa de impunidad sobre nuestra memoria común. La reapertura de los juicios a partir de 2005 pudo asentar su legitimidad sobre la afirmación de que los crímenes habían quedado impunes -y tanto caló esta convicción en muchos que hasta pudo llevar a ignorar, por momentos, la existencia del histórico Juicio a las Juntas de $1985^{23}$. En nombre de la lucha contra lo que se construía como el triunfo de la impunidad pudo legitimar en los hechos el desconocimiento de elementos esenciales del estado de derecho. Considero que es un debate esencial preguntarnos por qué estamos, como la mayoría de la Corte Suprema de entonces, de acuerdo con la legitimidad de hacerlo, o por qué estamos, como Andrés D’Alessio, juez del Juicio a las Juntas, radicalmente en $\operatorname{contra}^{24}$. En nombre de la lucha contra aquella impunidad, la reapertura pudo también soslayar las preguntas que no debemos dejar de hacernos: si admitimos -y yo estaría dispuesta a considerarlo- que nuestro sentido ofendido de justicia es una guía moral que nos impone que crímenes horrendos no queden impunes, ¿es nuestro sentido ofendido de justicia un criterio suficiente para establecer con precisión cuáles crímenes no pueden quedar impunes, aunque para ellos debamos

\footnotetext{
22 En un acontecimiento que conmocionó a todo el país, Ignacio Montoya Carlotto, nacido en cautiverio y dado en adopción por los asesinos de su madre Laura Carlotto, hija de la presidenta de la asociación Abuelas de Plaza de Mayo, recuperó su identidad en agosto de 2014. Desde entonces ha resultado visible el interés de diferentes voceros de los derechos humanos de sostener el deseo de Ignacio de proteger a sus padres de crianza -quienes lo anotaron como propio y, por ende, pueden ser condenados como cómplices del delito de apropiación de menores- de la persecución de la justicia, contrariando también aquí la postura habitual en casos similares.

${ }^{23}$ El caso más notorio de este olvido, pero ciertamente no el único, fue el del entonces presidente Néstor Kirchner en la Escuela de Mecánica de la Armada (ESMA) el 24 de marzo de 2004, en ocasión de la firma del Convenio para la creación del Museo de la Memoria en la ESMA, cuando expresó que venía «a pedir perdón de parte del Estado nacional por la vergüenza de haber callado durante 20 años de democracia por tantas atrocidades». Disponible en: http://www.presidencia.gov.ar/index.php?option=com_conten t\&view $=$ article\&id $=24549 \&$ catid=28:discursos-ant (último ingreso: 10/10/2014) .

${ }^{24}$ Véase Andrés D’Alessio, Los delitos de lesa humanidad, Buenos Aires, Abeledo Perrot, 2008.
} 
olvidar aquellos principios básicos del orden jurídico? Si nuestro sentido ofendido de justicia nos habilita -ya sea sobre la «remisión arcaica a lo justo» (Arendt), ya sobre nuestra "conciencia moral» (Strassera)- a saber qué es un crimen horrendo y aberrante, ¿̇nos habilita también a saber hasta dónde se extiende la culpabilidad que legitima aquel olvido, y a perseguir como criminales del crimen imprescriptible (y retroactivo) de lesa humanidad desde quiénes ordenaron esos crímenes desde la cúpula del poder -Videla, Massera, Suárez Mason, para citar a algunos- hasta el subteniente que encabezó un traslado, o los padres de Ignacio Montoya Carlotto, o el periodista que fraguó una entrevista con un desaparecido? ${ }^{25}$.

En otras palabras, la reapertura de los juicios en 2003/2005 acarrea para mí a la vez, entremezcladas, la afirmación del sentido ofendido de justicia frente a un crimen horrendo que considera que quedó y no puede quedar impune -esto es, acarrea la afirmación de un sentido de la justicia-, pero también junto con esta afirmación más abstracta, más elemental, acarrea la auto-adjudicación de la capacidad de instituir, positivamente, la distinción entre lo justo y lo injusto. El peligro que percibo, en el olvido de las preguntas que esta reapertura ha acallado, es que la celebración actual del accionar de la justicia encubra, en demasiadas ocasiones, con demasiada facilidad, la pasión retributiva, que lejos de deplorar -en clave trágica- la excepcionalidad a la que el sentido ofendido de justicia debe hacer frente, parece gozar con ella. En la aparición, aquí y allá, de excepciones a la excepción -en el caso Milani, en el caso Hurban o en otros tantos casos que podrían aparecer en una ampliación creciente de la punibilidad hacia las zonas grises del pasado reciente-, se manifiestan los problemas que la pasión retributiva ha logrado hasta entonces soslayar y se abre, a mis ojos, la posibilidad de que nos interroguemos sobre los problemas políticos, jurídicos y morales que la reapertura de los juicios desde 2003/2005 no debería dejar de evocar.

\footnotetext{
${ }^{25}$ Recordemos que dado el tiempo transcurrido desde los hechos, sólo son susceptibles de persecución penal los delitos encuadrados bajo la figura imprescriptible del crimen de lesa humanidad. Y ciertamente, cabe que nos preguntemos si el carácter moralmente repugnante de algunas acciones -como la del periodista evocado- justifica su identificación con un crimen de lesa humanidad.
} 


\section{Registro bibliográfico}

HILB, CLAUDIA

«De Eichmann en Jerusalén a los ‘Juicios» en Argentina (reflexiones situadas)», en: ESTUDIOS SOCIALES, revista universitaria semestral, año $X X V, n^{\circ} 48$, Santa Fe, Argentina, Universidad Nacional del Litoral, primer semestre de 2015, pp. 91-104.
Recibido: 23 / 11 / 2014

Aprobado: 15 / 02 / 2015 